\section{Parks in Peril: People, Politics and Protected Areas.}

Katrina Brandon, Kent H. Redford e Steven E. Sanderson (eds.)

Washington, DC/Covelo, California

The Nature Conservancy/ Island Press, 1998.

\section{PEDRO CASTELO BRANCO SILVEIRA*}

Os mecanismos formais de conservação da natureza estão passando, nos últimos dez ou quinze anos, por um enorme debate, tanto no plano conceitual quanto no plano da ação. A implantação de áreas protegidas em todo o mundo, muitas delas não prevendo presença humana, a ascensão do desenvolvimento sustentável como panacéia para uma civilização insustentável e, principalmente, a incorporação do(s) ambientalismo(s) nos discursos de diversos segmentos e grupos sociais têm gerado enormes polêmicas sobre o que é conservação da natureza e como deve ser realizada.

Nos últimos anos têm-se iniciado em todo o planeta estudos sobre os conflitos que emergiram após a implantação de áreas naturais protegidas. Entretanto, dada a multiplicidade de experiências e resultados das chamadas unidades de conservação, o campo para pesquisa sobre o tema está longe de se esgotar, e o debate permanece acalorado. Múltiplas também são as matizes destes conflitos, com suas características próprias, refletindo

* Pedro Castelo Branco Silveira é biólogo, mestre em antropologia social pela Unicamp e pesquisador associado do Nepam/Unicamp. conflitos locais pré-existentes e diferentes processos sociais na história da implantação destas área protegidas.

Parks in Peril-People, Politics and Protected Areas é uma coletânea de textos que compõem a auto-avaliação do homônimo mega-programa de conservação da ONG americana The Nature Conservancy (TNC). Propõe-se a ser uma análise completa, em diversas escalas, de conflitos, ameaças e possibilidades institucionais relativas a nove parques na América Latina e Caribe que fazem parte do programa, procurando aliar pontos de vista políticos, ecológicos e sociais. Nada mais atual e adequado na área ambiental do que um programa de pesquisa que conecta ciências humanas e ciências naturais e analisa fenômenos em escalas local, regional e internacional. Esta abordagem, ausente em grande parte dos trabalhos sobre o tema, confere respaldo e pertinência ao livro. Entretanto, ao invés de laurear o trabalho como uma versão definitiva da situação dos parques na porção pobre da América, é fundamental que o leitor compreenda o lugar ocupado pela TNC no debate em torno da conservação.

Os parques foram criados, em uma visão geral, segundo um modelo americano, como monumentos naturais a serem protegidos do avanço da civilização, para deleite das sucessivas gerações civilizadas. Localmente, como os diversos estudos de caso do livro mostram, tal criação dependeu de lobbies diversos de grupos, às vezes indivíduos, sem maiores discussões gerais.

Nos anos de 1990, o termo desenvolvimento sustentável ganha força no cenário mundial. Grande parte das políticas ambientais (e recursos) passa a 
privilegiar projetos que procurem transformar o desenvolvimento em algo reconciliável com o ambiente. A idéia de sustentabilidade, assumindo diversos significados conforme o grupo usuário do termo, passa a ser uma idéia-chave.

Concomitantemente, o modelo de proteção aos recursos naturais por meio da exclusão da presença humana passa a ser duramente criticado pelos conflitos que criara em todo o mundo. Alguns movimentos populares passam então a reivindicar o papel de defensores da biodiversidade, tais como organizações indígenas, seringueiros e organizações camponesas. Este processo gera instituições como as Reservas Extrativistas brasileiras. A conservação privada, visando bioprospecção e/ou marketing ambiental, também começa a crescer utilizando o discurso do desenvolvimento sustentável.

Redes de unidades de conservação passam a englobar tanto áreas em que a presença humana é desejável, segundo certos critérios, quanto às áreas em que o uso humano seria proibido. A distância entre os modelos internacionais e as realidades locais da conservação é visível, face aos múltiplos processos sociais que muitas vezes tornam inviáveis idéias como a de que deve haver nos sítios de conservação uma área núcleo, uma área tampão e uma área de uso controlado.

Muitos dos cientistas da conservação e membros de ONGs passam a apostar em projetos de envolvimento da população local na conservação, tais como planos de manejo sustentável e suporte à organização local. As áreas em que o uso humano é proibido passam a ser desprestigiadas. Uma posição polar que se cria é a de que uso humano histórico faz parte da dinâmica de muitas das formações florestais dos neotrópicos.

Os anos se passam e também as experiências de uso sustentável começam a ter uma história a ser analisada. Neste momento, uma nova posição polar é tomada pelos críticos do uso sustentável, aqueles que apostam que conservação com sucesso se faz sem presença humana. É desta posição do debate que fala a Nature Conservancy, fazendo parte desta tendência que separa a verdadeira conservação (aquela que se faz nos parques bem sucedidos) da conservação aliada ao uso, supostamente baseada em slogans populistas. É interessante notar que dois dos editores do livro, Katrina Brandon e Kent Redford, já estiveram, durante a década de 1990, alinhados a posições mais moderadas no debate, apropriando-se do mesmo discurso em voga no período imediatamente posterior à Rio 92, que hoje criticam. Estas posições podem ser vistas em livros como "Conservation of Neotropical Parks" (ref) e "People and Parks- Linking Protected Area Management with Local Communities" (WELLS \& BRANDON, 1992).

A idéia do livro é simples, e colocada de forma clara já no prefácio e na introdução: as áreas naturais protegidas são o pilar da conservação da natureza e não devem carregar toda a responsabilidade pelo desenvolvimento sustentável. Trocando em miúdos, o livro traz implícita a idéia de que a conservação da natureza não deve buscar necessariamente aliança com lutas sociais para se estabelecer como legítima e alcançar seus objetivos. A ameaça colocada é o suposto fenômeno da transformação de parques em áreas de uso sustentável e o estabelecimento preferencial, na última 
década, de unidades de conservação com uso ao invés de unidades sem uso previsto.

O livro é composto de três partes. A primeira, "Neotropical Parks: Challenges and Context", é composta de três artigos que, além de explicar o contexto do programa Parks in Peril deixam claras as bases argumentativas da Nature Conservancy a respeito da conservação. $\mathrm{Na}$ segunda parte, denominada Nine Neotropical Parks, são descritas as situações específicas de nove parques latino americanos e caribenhos (México, Guatemala, Peru, Costa Rica, República Dominicana, Bolívia, Equador e Belize) onde há parcerias entre Nature Conservancy e ONGs locais para a gestão da conservação. A terceira parte, denominada Reality and Reaction: Saving Neotropical Parks, traz os quatro capítulos finais, comparando os casos e esboçando as conclusões.

Apesar do nome da parte final do livro, Parks in Peril é mais do que uma espécie de manifesto de defesa dos parques com uma roupagem de pesquisa científica multidisciplinar. É talvez uma das únicas publicações sobre o tema que coloca claramente um ponto importante do debate: existe uma luta política para se determinar quem é o detentor do significado do termo biodiversidade. Os editores citam a indústria farmacêutica, os antropólogos, os etnobotânicos, as indústrias de melhoramento genético e as populações indígenas e tradicionais como alguns dos grupos que se apropriam do termo em forma de slogans como parks for people, sustainable development and use, grassroots community based conservation ou conservation for development.

No entanto, ao invés de verem esta apropriação do ambientalismo por múltiplas parcelas da sociedade como o inevitável mergulho da conservação em outras formas de conflitos sociais - em que não basta ter a posição de conservacionista e ser neutro em outras questões - os autores desqualificam as posições antagônicas com o argumento de que não têm base científica. Ou seja, se a questão da conservação da biodiversidade é política, não o deveria ser. Nesta visão, a ciência é quem tem a definição correta de biodiversidade e é quem deve dar as bases para as políticas de conservação. Ou seja, cientistas e cientistas-gestores são os reais detentores da verdade da conservação e deve-se procurar meios políticos e sociais para que tais verdades sejam implementadas. A crítica aos slogans do uso sustentável vem também por este viés: faltam estudos científicos sobre o que acontece quando tais slogans são utilizados para guiar ações.

Podemos classificar as posições dos autores ligados ao programa Parks in Peril como pragmáticas: conservar significa afastar atividades econômicas de uma área. Por trás desta posição pragmática vem implícita a idéia de que o mundo deve ser dividido em duas categorias de regiões: áreas de desenvolvimento e áreas de conservação. A crítica que fazem ao desenvolvimento sustentável vem no sentido de evitar que o desenvolvimento avance sobre as áreas de conservação sob o rótulo da sustentabilidade. Ou seja, a busca de diferentes formas de desenvolvimento deve ser feita fora das áreas de conservação. E onde quer que existam florestas, elas devem ser conservadas sob estes critérios. Esta idéia é claramente demonstrada no capítulo 16, quando os editores colocam:

"as escolhas que uma sociedade deve fazer são geralmente rígidas: carne ou os 
flamingos de Yucatán; ouro ou as florestas enevoadas Andinas; madeira ou as onças amazônicas; café ou os quetzals da Costa Rica; passeios de barco ou o Grande Recife de Corais Maia. Carne, café e outros recursos podem ser produzidos em muitos locais, mas os flamingos de Yucatán e as florestas enevoadas Andinas não." (p.463, minha tradução).

Flamingos são para áreas de conservação, café é para áreas de desenvolvimento (se invariavelmente a sociedade escolhe o ouro às florestas, a madeira às onças, porque será que não o fazem os conservacionistas da TNC?). O zoneamento do planeta, sob esta ótica, é feito por profissionais engravatados em seus escritórios e por equipes locais de conservação, preferencialmente ONGs parceiras da TNC. A participação local confunde-se com estratégias para cooptação da população local, ou "atividades de conquista da confiança local" (p. 74). No Capítulo 3, dedicado ao contexto social dos parques do programa, Barbara Dugelby e Michael Libby colocam como saída popular (e simpática) a contratação de moradores locais como guarda-parques, que teriam a tarefa de "educar" as comunidades sobre o parque e seus propósitos. Outras "ações sociais" dos que pretendem a conservação seriam o oferecimento de empregos de ajudantes de biólogos, cozinheiras e contratos temporários para construção de infra-estrutura dos parques. Entre as atividades desejáveis no entorno dos parques estão ecoturismo, agroecologia, criação de animais em cativeiro, aqüicultura, apicultura, artesanato e projetos de assistência à saúde. Tudo muito bonito, mas certamente desvinculado das realidades locais. Não é o caso aqui de incorrer em um tradicionalismo ortodoxo, mas de problematizar as inúmeras soluções prontas que historicamente vêm a ser aplicadas a populações pobres com modos específicos de organização social e de práticas com a natureza..

Parks in Peril é financiado pelo USAID e apoia ONGs dos países sede dos parques escolhidos para implementação do programa em cada parque. Um programa que mobiliza dinheiro do governo norteamericano para ONGs locais alinhadas com o interesse da TNC em última análise reflete as formas de ambientalismo privilegiadas pelo governo norteamericano para os países latinoamericanos. Um modelo que procura conseguir seus objetivos de conservação no plano local pela cooptação das populações residentes certamente está longe de ser compatível com idéias como democracia, cidadania, participação. Se, assim como a sustentabilidade, tais palavras signifiquem slogans vazios para a TNC, estaríamos diante do que em outros tempos seria chamado imperialismo.

Esta postura polar, entretanto, não deve mascarar a necessidade imediata de conservação dos ecossistemas neotropicais nativos: os impactos e situações conflitivas mostrados são reais e graves. Duas contribuições importantes são trazidas pela crítica da TNC aos seus opositores. Primeiro, a idéia de que o chamado uso sustentável tem limites com relação à conservação da natureza, mesmo que o objetivo seja apenas a conservação de paisagens ou espécies. E, em segundo lugar, que a comparação de análises de contextos sociais em diferentes escalas ajuda a compreender melhor os conflitos em torno da 
conservação. Estas duas questões abrem espaço para que uma extensa agenda de pesquisa em ciências naturais e sociais possa ser desenvolvida, considerando-se a interação dinâmica entre diferentes atores sociais e a não pertinência de afirmações simplistas tais como "populações tradicionais estão em equilíbrio com a natureza" ou "populações indígenas mudam rapidamente rumo à economia de mercado".

Em verdade, são escassos atualmente os estudos sobre os efeitos de projetos de uso sustentável de recursos, em muito devido ao impacto de tais projetos só poder ser medido a médio e longo prazo, em parte por serem processos sociais em curso que podem tomar rumos diversos em sua história, dependendo da forma como interagirem com outros elementos políticos, sociais e econômicos. Se falta suporte científico, em muito é devido a falta de cientistas efetivamente envolvidos nos projetos, trazendo para o diálogo o conhecimento científico. Se biodiversidade tem vários sentidos, considerar os sentidos que todos os outros dão como simples slogans não ajuda em sua compreensão. Certamente, entre o líder indígena e o executivo de multinacional existe uma diferença muito grande em projeto de futuro sustentável.

$\bigcirc$ que os autores analisam, mas não dão o devido valor, é que grande parte dos conflitos se deram pela forma como os parques foram implantados, alienígenas em um contextos nacionais mais amplos e agravadores das situações de miséria e exploração dos países centro e sul-americanos, situações muitas vezes postas pelo mesmo processo de desenvolvimento que destrói ecossistemas nativos. Grande parte da gênese dos conflitos em curso está, portanto, na forma como o zoneamento de áreas de desenvolvimento e de conservação foi realizado. Apesar da análise de múltipla escala, os projetos de desenvolvimento e a ação de populações indígenas são medidos com o mesmo parâmetro: o de ameaça à (verdadeira) biodiversidade. As populações humanas do entorno e interior do parque são vistas como grupos culturais frágeis perante a força do mercado, e incapazes de ter voz e conceitos próprios sobre sua situação. Os únicos parceiros possíveis são os preservacionistas locais. As áreas de desenvolvimento são áreas perdidas para a conservação, e se nelas haverá projetos de sustentabilidade não é um interesse da ciência da conservação, a não ser que estejam no entorno de unidades de conservação.

$O$ pragmatismo que aposta em soluções "de cima para baixo" como única possibilidade para o estabelecimento de conservação efetiva (p.462) nos remete à distância que as resoluções oficiais sobre o desenvolvimento sustentável têm da realidade concreta. Se a conservação da natureza é hoje quase exclusivamente feita nas áreas de conservação, sejam elas com ou sem uso, isto nos faz pensar no quanto estamos longe de qualquer coisa semelhante à sustentabilidade. Será que os mesmos mecanismos opressivos nortesul historicamente aplicados na América Latina seriam a solução para a efetiva conservação da natureza? A TNC imagina que sim. Há conhecimento sendo produzido mostrando que não. Controverso, Parks in Peril é uma leitura instigante que nos faz pensar sobre os destinos da conservação da natureza. 


\section{BIBLIOGRAFIA}

REDFORD, K. \& PADOCH, C. (eds) Conservation of Neotropical Forests. Columbia University Press, New York, 1992.

WELLS, M. \& BRANDON, K. (eds) People and Parks: linking protected areas with local communities. Washington DC, Banco Mundial, WWF, USAID, 1992. 